Supporting Information for

\title{
Fluorous-Phase Ion-Selective pH Electrodes: Electrode Body and Ionophore Optimization for Measurements in the Physiological pH Range
}

\author{
Xin V. Chen, Maral P.S. Mousavi, ${ }^{1}$ and Philippe Bühlmann*
}

Department of Chemistry, University of Minnesota, 207 Pleasant St. SE, Minneapolis, MN 55455, United States

*buhlmann@umn.edu

${ }^{1}$ Current address: Dept. Biomedical Engineering, University of Southern California, 1042 Downey Way, Los Angeles CA 90089

\section{Table of Contents}

1. Characterization of the Fluorophilic Ionophore $\mathrm{N}\left[\mathrm{CH}_{2} \mathrm{CH}_{2} \mathrm{CH}_{2} \mathrm{CH}_{2} \mathrm{R}_{\mathrm{f}}\right]_{3}$ (2)

Figure S1. ${ }^{1} \mathrm{H}$ NMR spectrum of the fluorophilic ionophore $\mathrm{N}\left[\mathrm{CH}_{2} \mathrm{CH}_{2} \mathrm{CH}_{2} \mathrm{CH}_{2} \mathrm{R}_{\mathrm{f}}\right]_{3}$ (2).

Figure S2. Electrospray mass spectrum of the fluorophilic ionophore $\mathrm{N}\left[\mathrm{CH}_{2} \mathrm{CH}_{2} \mathrm{CH}_{2} \mathrm{CH}_{2} \mathrm{R}_{\mathrm{f}}\right]_{3}$ (2)

2. Design of the Electrode Body

Figure S3. 3D view of outer electrode body piece

Figure S4. 3D view of inner electrode body piece

Figure S5. 3D view of screw cap and the inner electrode body piece mounted inside the outer electrode body piece

Figure S6. 3D views of cross-sections of the outer electrode body piece, inner electrode body piece, and the whole assembly with the screw cap

Figure S7. 3D view of a cross-section of the inner and outer electrode body pieces

Figure S8. Detailed dimensions of the electrode body

3. Selectivity Measurements

Details of the selectivity determination. 


\section{Characterization of the Fluorophilic Ionophore $\mathrm{N}\left[\mathrm{CH}_{2} \mathrm{CH}_{2} \mathrm{CH}_{2} \mathrm{CH}_{2} \mathrm{R}_{\mathrm{f8}}\right]_{3}$ (2)}

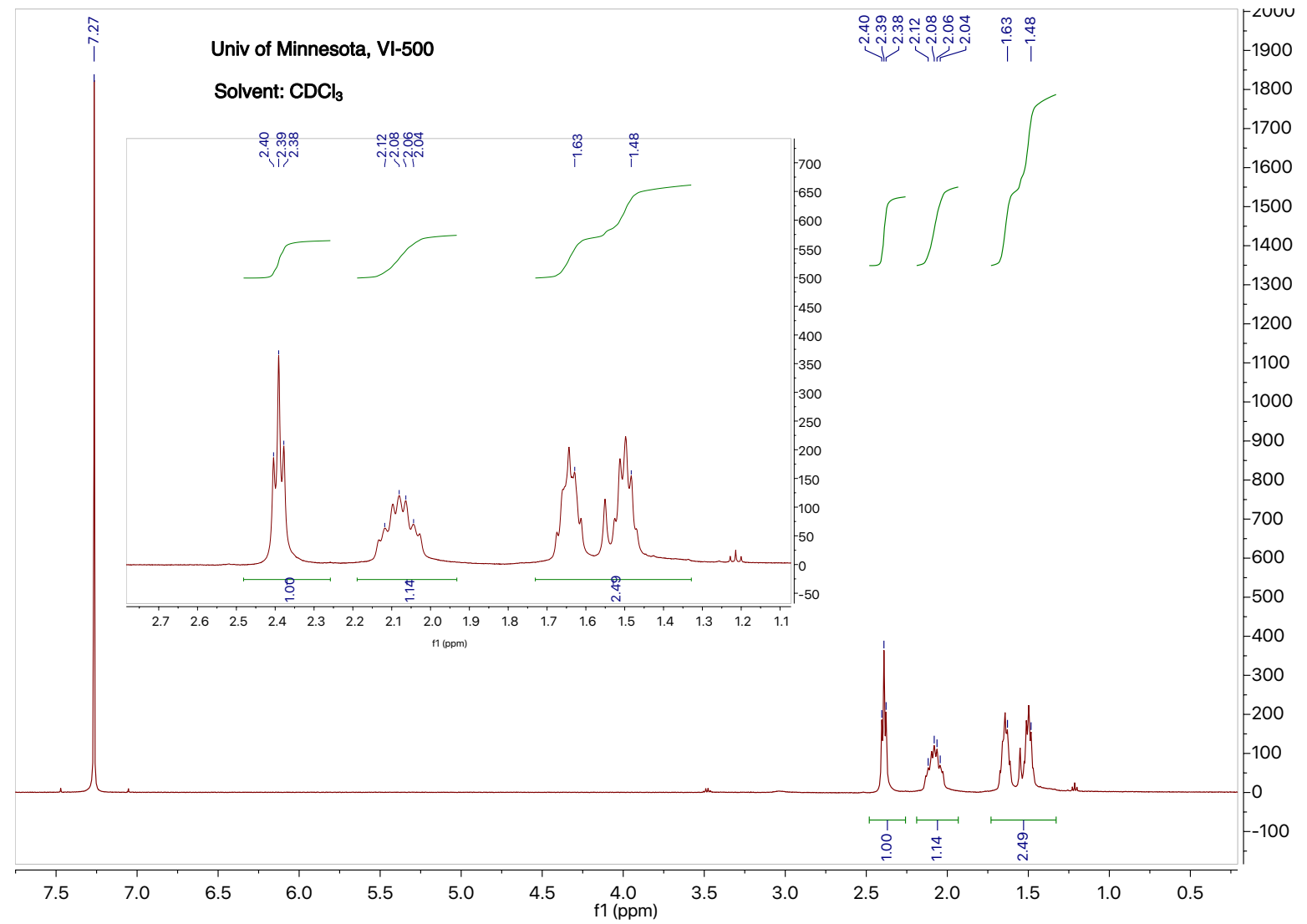

Figure S1. ${ }^{1} \mathrm{H}$ NMR spectrum of the fluorophilic ionophore $\mathrm{N}\left[\mathrm{CH}_{2} \mathrm{CH}_{2} \mathrm{CH}_{2} \mathrm{CH}_{2} \mathrm{R}_{\mathrm{f}}\right]_{3}$ (2). 


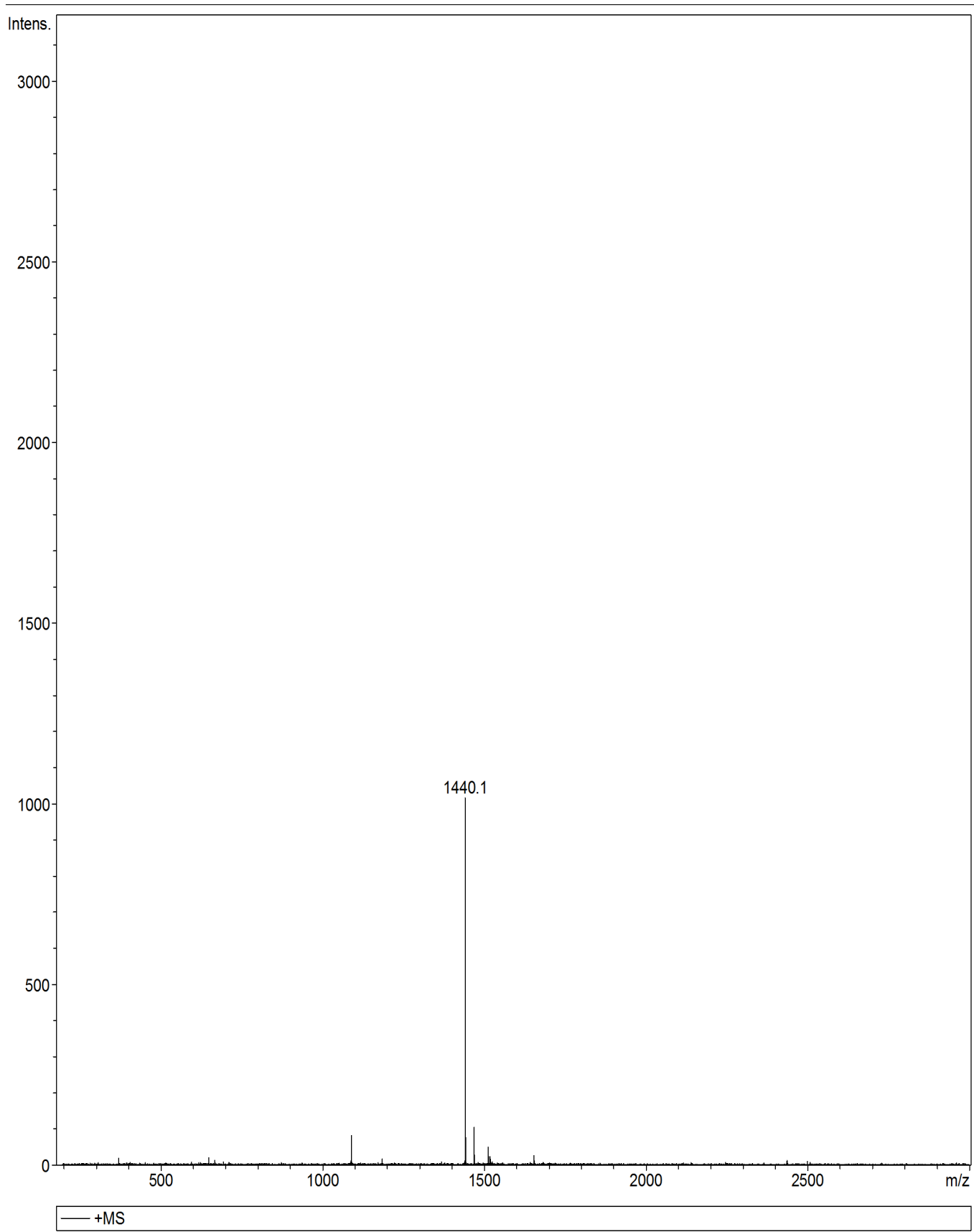

Bruker Daltonics DataAnalysis 3.4

Electrospary - TOF

Figure S2. Electrospray mass spectrum of the fluorophilic ionophore $\mathrm{N}\left[\mathrm{CH}_{2} \mathrm{CH}_{2} \mathrm{CH}_{2} \mathrm{CH}_{2} \mathrm{R}_{\mathrm{f}}\right]_{3}$ (2). 


\section{Design of the Electrode Body}

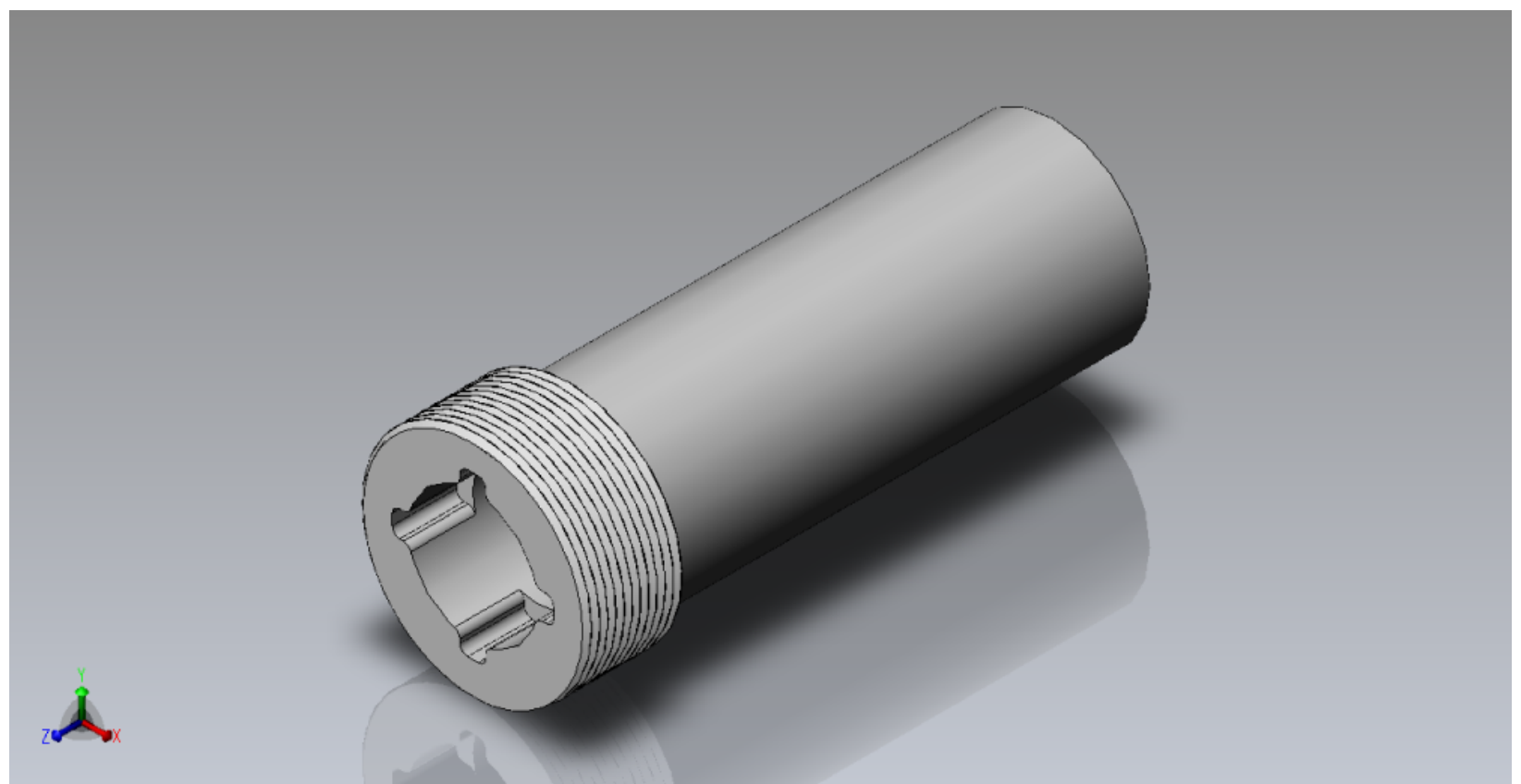

Figure S3. 3D view of outer electrode body piece (upper end shown in front). Four locking slots (at $90^{\circ}$ to each other) securely hold the lugs of the inner electrode body piece (see Figs. S4 and S5), preventing the inner body piece from rotating within the outer electrode body piece when the screw cap is mounted.

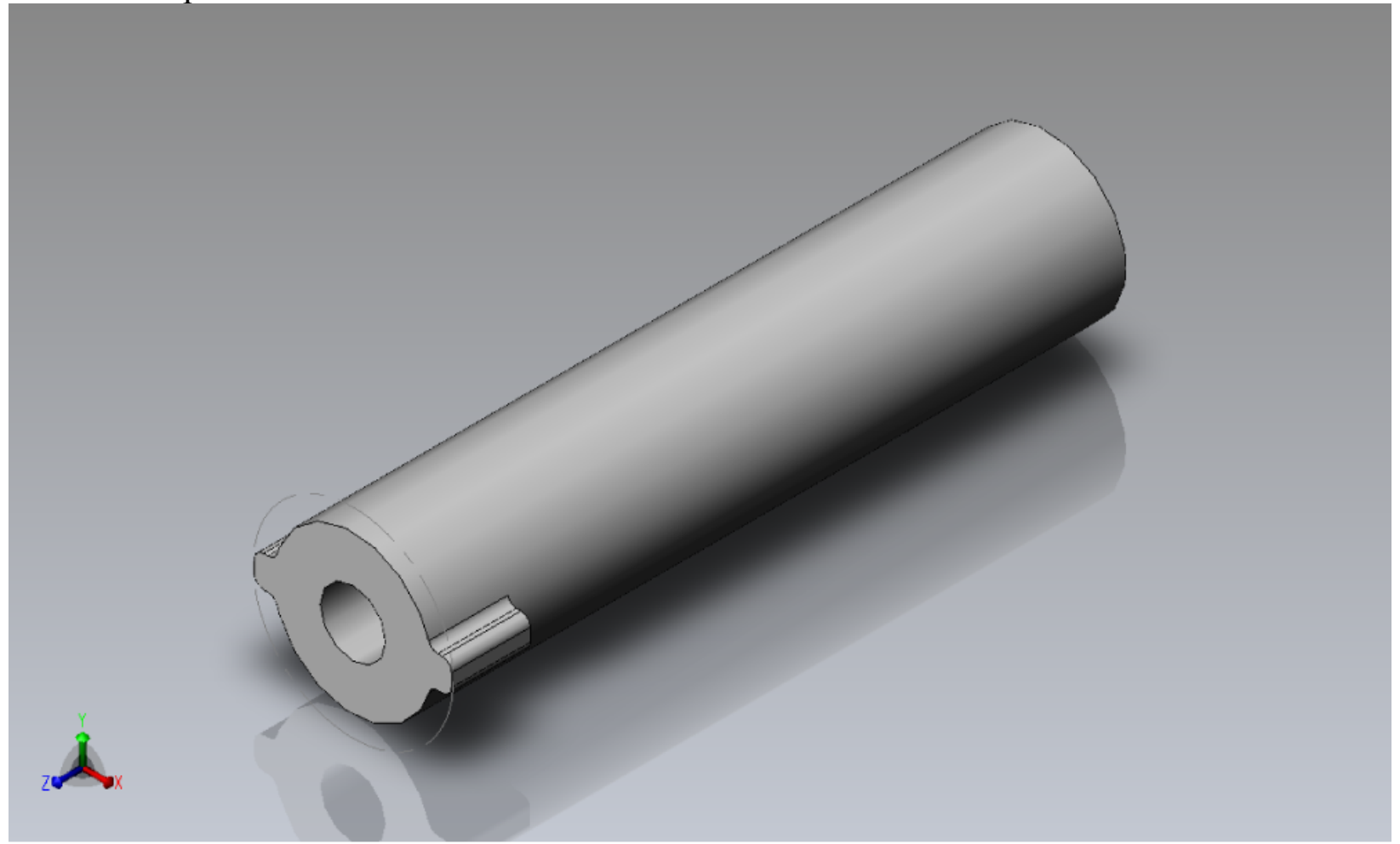

Figure S4. 3D view of inner electrode body piece (upper end in front). Two lugs (at $180^{\circ}$ to each other) securely fit into locking slots of the inner electrode body piece (see Figs. S3 and S5). 


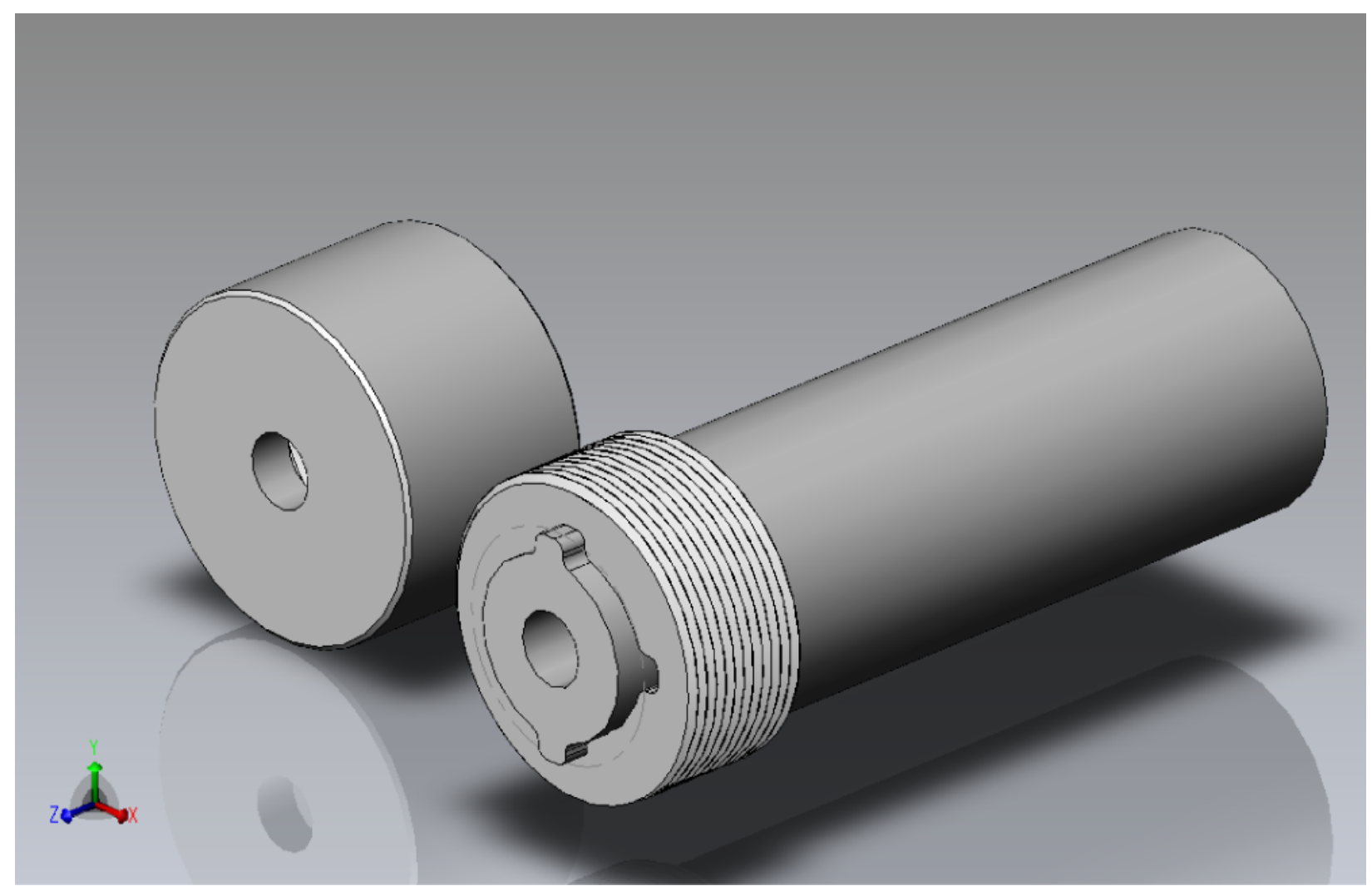

Figure S5. 3D view of screw cap (left) and the inner electrode body piece mounted inside the outer electrode body piece (right). The two lugs of the inner electrode body piece fit into the locking slots of the outer body piece. When the cap is screwed onto the outer body piece, it exerts pressure onto the inner body piece, pushing it onto the sensing membrane (located between the inner and outer body pieces) without causing any rotating motion of the membrane. This ensures a tight and smooth mechanical seal of the membrane. 


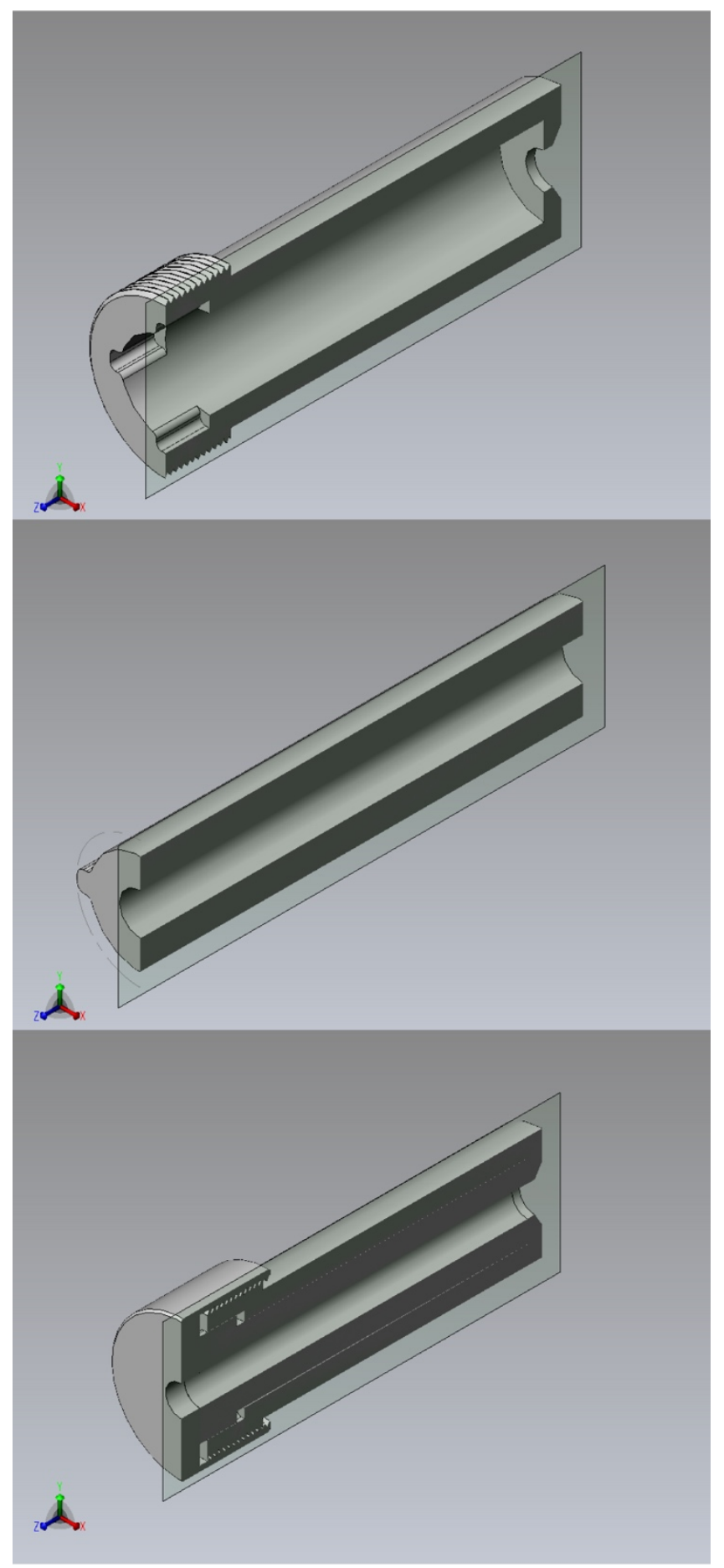

Figure S6. 3D views of cross-sections of the outer electrode body piece (top), inner electrode body piece (middle), and the whole assembly with the screw cap (bottom). 


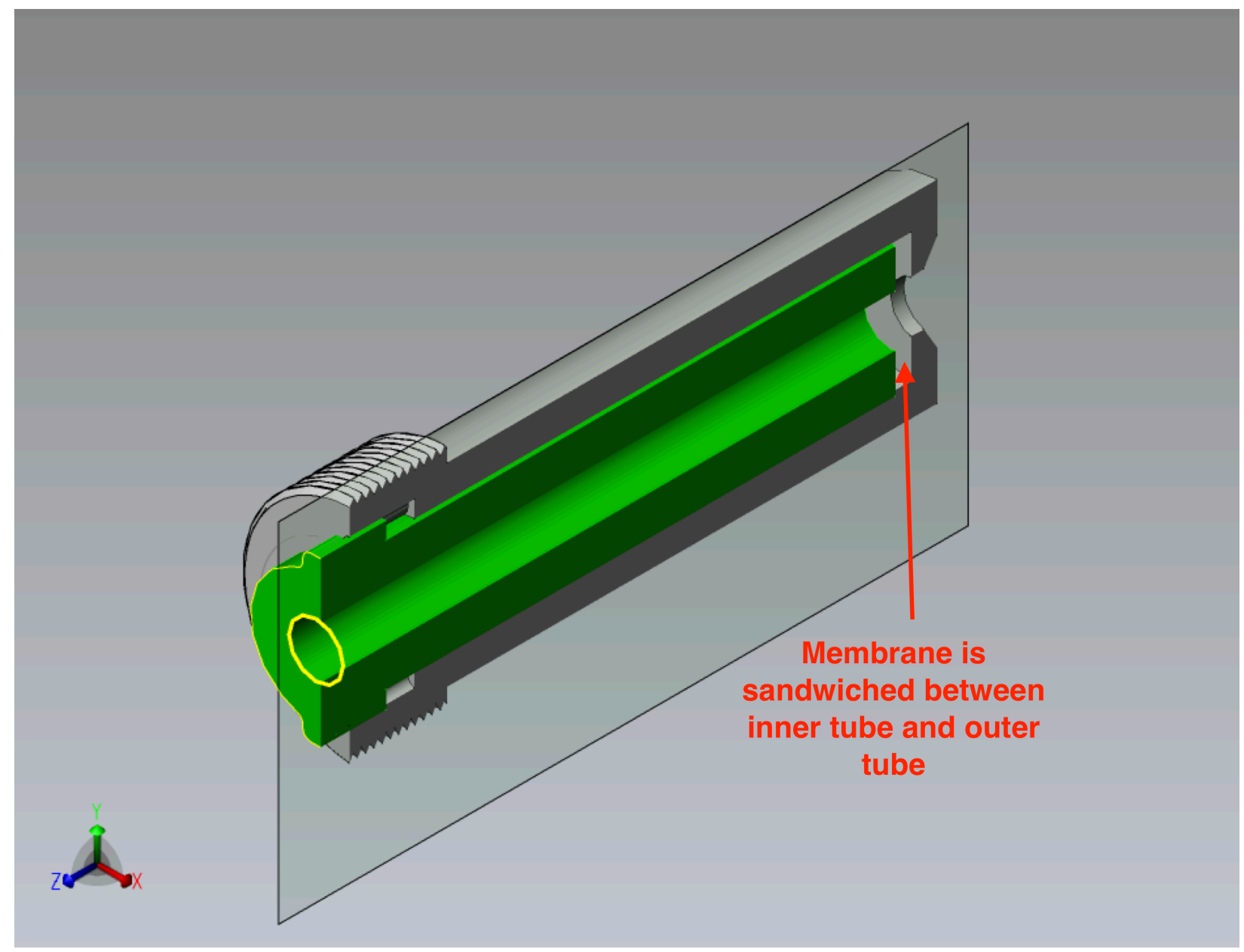

Figure S7. 3D view of a cross-section of the inner and outer electrode body pieces, illustrating where the membrane is located.

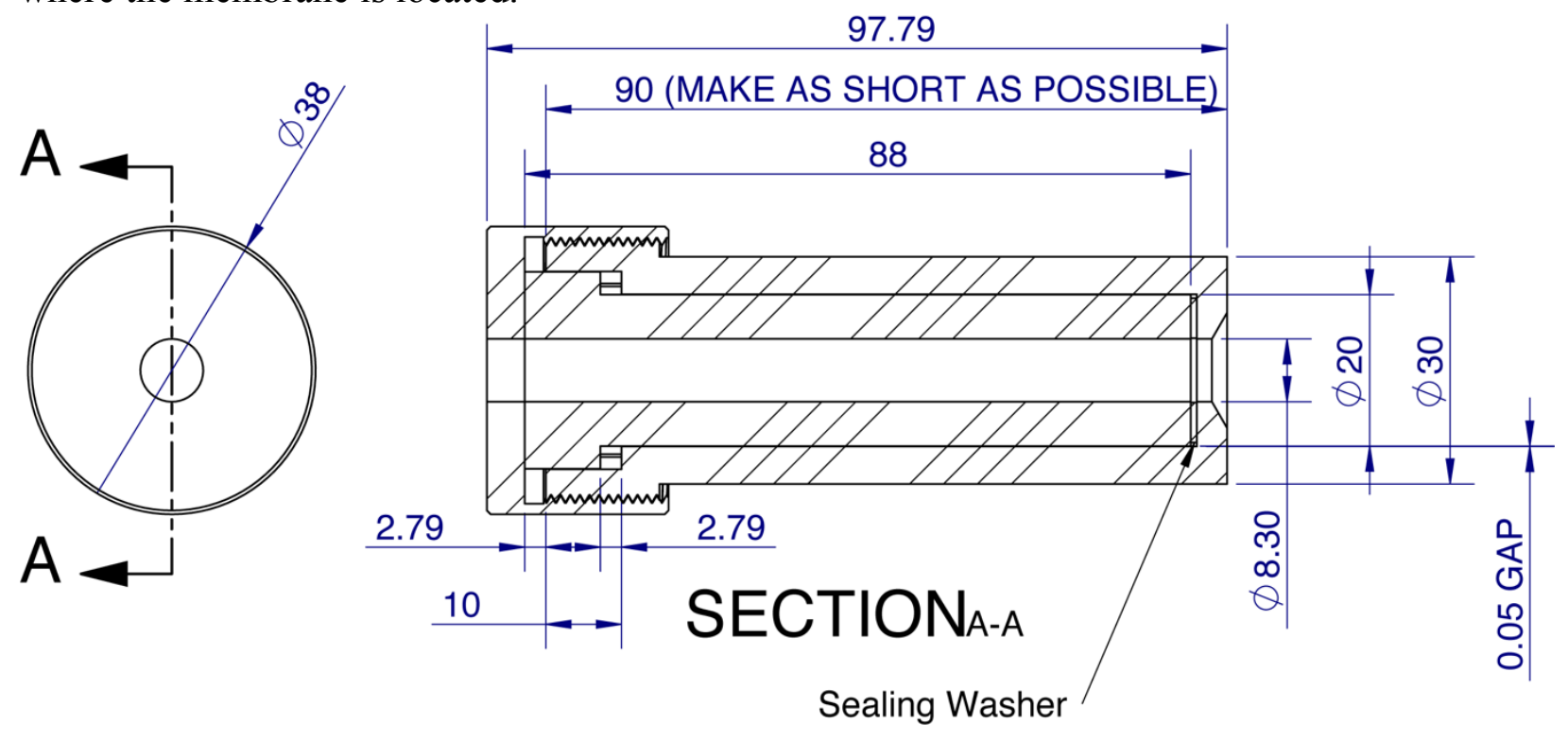

Figure S8. Detailed dimensions of the electrode body (unit: $\mathrm{mm}$ ). 


\section{Selectivity Measurements}

The non-coordinating reference ion considered initially for the determination of the $\mathrm{p} K_{\mathrm{a}}$ of $\mathrm{N}\left[\mathrm{CH}_{2} \mathrm{CH}_{2} \mathrm{CH}_{2} \mathrm{CH}_{2} \mathrm{R}_{\mathrm{f}}\right]_{3}$ in the fluorous phase was the tetraphenylphosphonium ion $\left(\mathrm{PPh}_{4}^{+}\right)$. However, direct measurements of selectivities for $\mathrm{PPh}_{4}{ }^{+}$with respect to $\mathrm{H}^{+}$failed because in such experiments $\mathrm{PPh}_{4}{ }^{+}$and $\mathrm{H}^{+}$did not give the required Nernstian responses. Therefore, it was also attempted to determine this selectivity coefficient using a "selectivity ladder", i.e., by measuring the SSM selectivities for $\mathrm{NPr}_{4}{ }^{+}$and $\mathrm{NBu}_{4}{ }^{+}$, which exhibit selectivities intermediate between $\mathrm{H}^{+}$ and $\mathrm{PPh}_{4}{ }^{+}$. Then, the selectivity for $\mathrm{PPh}_{4}{ }^{+}$with respect to $\mathrm{H}^{+}$was computed with eq $\mathrm{S} 1$ :

$$
\log K_{\mathrm{H}, \mathrm{PPh}_{4}}^{\mathrm{pot}}=\log K_{\mathrm{H}, \mathrm{NPr}_{4}}^{\mathrm{pot}}+\log K_{\mathrm{NPr}_{4}, \mathrm{NBu}_{4}}^{\mathrm{pot}}+\log K_{\mathrm{NBu}_{4}, \mathrm{PPh}_{4}}^{\mathrm{pot}}
$$

The $\mathrm{p} K_{\mathrm{a}}$ value determined for ionophore 2 on the basis of $\log K_{\mathrm{H}, \mathrm{PPh}_{4}}^{\mathrm{pot}}$ and eqs 2 and 3 was $15.8 \pm$ 1.2 , which is higher than the value previously reported for ionophore 3 with $-\left(\mathrm{CH}_{2}\right)_{5}$ - spacers (15.4). This is likely due to errors associated with the indirect measurement of multiple selectivity coefficients using the selectivity ladder approach. In the measurement of each of these selectivity coefficients, intercepts of calibration curves are used to calculate selectivity coefficients. Therefore, errors may come from Nernstian slopes ranging between 56 and 63 $\mathrm{mV} /$ decade, which affect intercepts and propagates errors into $\log K_{\mathrm{H}, \mathrm{PPh}_{4}}^{\mathrm{pot}}$.

\section{Acknowledgement}

We thank Peter Ness from the College of Science and Engineering Machine Shop, University of Minnesota, for help with the design and fabrication of the electrode bodies. 